\title{
Effects of vineyard agricultural practices on the diversity of macroinvertebrates
}

\author{
I.J. Ramos ${ }^{1, \text { a }}$, J.A. Ribeiro ${ }^{2}$, and D. Figueiredo ${ }^{3}$ \\ ${ }^{1}$ University of Évora, School of Sciences and Technology, Department of Landscape, Environment and Planning | Researcher at \\ Interdisciplinary Centre of Social Sciences - CICS.NOVA.UÉvora. Largo dos Colegiais, 2. 7004-516 Évora, Portugal \\ ${ }^{2}$ University of Évora, School of Sciences and Technology. Largo dos Colegiais, 2. 7004-516 Évora, Portugal \\ ${ }^{3}$ University of Évora, School of Sciences and Technology, Department of Biology | Researcher at Centre in Biodiversity and Genetic \\ Resources - CIBIO-UE. Largo dos Colegiais, 2. 7004-516 Évora, Portugal
}

\begin{abstract}
In Europe, agriculture represents the dominant land use and there is a substantial part of biodiversity associated with those habitats. Therefore, conservation studies should direct to agriculture fields aiming to minimize the biodiversity losses. Vineyards could play a key role in producing win-win solutions for agriculture and biodiversity conservation, as an entrance point of sustainable practices in agriculture management. This study aims to evaluate the influence of different agriculture practices on macroinvertebrate diversity and in the productivity of the vineyards. Comparing these variables, we hope to determine the most sustainable agriculture practices, to suggest conservation measures to enhance sustainability and improve biodiversity in the vineyards. We are comparing Coleoptera, Hymenoptera and Hemiptera diversity and levels of productivity in three differently managed vineyards: conventional, organic and integrated production with controlled doses of chemicals (optidose). Macroinvertebrates will be sampled by pitfalls and colour plates. Study area is Herdade dos Pinheiros of Fundação Eugénio de Almeida, in Évora (Alentejo, Portugal). We expect to find higher macroinvertebrates diversity where there is less disturbance, as in the organic vineyard. And the contrary for the conventional. Also, we are expecting to find little diversity of Hemiptera when there are higher levels of Coleoptera and Hymenoptera diversity, because that means biological control is acting. Finally, we hope to find the best agriculture measures to enhance sustainability and improve biodiversity in vineyards and surrounding areas.
\end{abstract}

\section{Introduction}

In Europe, agriculture represents the dominant land use and there is a substantial part of biodiversity connected to those habitats. Therefore, it is important for conservation biology to focus on agriculture landscapes and all the biodiversity within [1].

There has been a major intensification in agriculture practices over the past 60 years that leads to a great loss of biodiversity in agriculture landscapes [2]. Furthermore, this intensification of agriculture practices followed by habitat degradation and increase of the landscape homogeneity are the most important factors that increase the biodiversity loss in the current days [1].

The simplification of the agriculture systems affects many ecosystem services as productivity, biological control, polinization and decomposition [3]. On the other hand, it also affects, in long term, the soil fertility, water conservation and purification and the climate variations [4].

Nowadays, the ecological footprint of agriculture is bigger and bigger to satisfy the needs of a growing

\footnotetext{
${ }^{a}$ With the financial support of FCT- Fundação para a Ciência $e$ a Tecnologia, I.P., through National funds, under the project «UID/SOC/04647/2013》- CICS.NOVA, Interdisciplinary Centre of Social Sciences of the Universidade Nova de Lisboa.
}

world population. But it is important to notice that agricultural systems can be managed in a sustainable way that prevents the loss of biodiversity and enables good levels of productivity [5].

Viticulture is one of the most important and influent sectors of agriculture. In this sense, Viers et al. (2013), proposed the term "Vinecology" - the integration of ecological and viticulture practices - to produce win-win solutions for wine production and nature conservation. This way, viticulture can be an entrance point for sustainable practices in agricultural landscapes [6].

The present study is based on project PSVA - Projeto de Desenvolvimento do Plano de Sustentabilidade para os Vinhos do Alentejo (Development Project of Sustainable Plan for the Alentejo Wines). This project is an initiative of CVRA (Comissão Vitivinícola Regional Alentejana) and the University of Évora (Portugal) that aims to develop better environmental, economic and social measures in the viticulture of the Alentejo region, promoting the importance of sustainability in agriculture. ${ }^{1}$

We aim to evaluate the index of biodiversity in three differently managed vineyards. Thus, we are going to compare the biodiversity between an organic

\footnotetext{
1 http://sustentabilidade.vinhosdoalentejo.pt/pt/ programa-de-sustentabilidade-dos-vinhos-doalentejo
}

(1) The Authors, published by EDP Sciences. This is an Open Access article distributed under the terms of the Creative Commons Attribution License 4.0 (http://creativecommons.org/licenses/by/4.0/). 
vineyard, an optidose integrated production vineyard and a conventional vineyard. Furthermore, we will measure the levels of productivity in all the three different vineyards. The goal is to find out the most sustainable practices that allow great levels of productivity, to suggest conservation measures to enhance sustainability and improve biodiversity in vineyards.

Studies aiming to promote biodiversity need indicators to evaluate and measure the impacts of different agricultural practices in that biodiversity. For all the above reasons we are investigating the biodiversity of three groups of macroinvertebrates: Coleoptera, Hymenoptera and Hemiptera. These are powerful indicators of biodiversity and ecosystems quality because they respond to agricultural practices variations. Invertebrates are connected to viticulture because they participate in polinization, soil conditioning and nutrient cycle [7].

\section{Vineyard management}

\subsection{Organic vineyard}

In an organic vineyard the management practices account for the natural balance of the environment and respect the natural cycles and systems of the soil, plants and animals. The most important principles about organic management in vineyards are keeping and enhancing biodiversity, protecting habitats and promoting the use of renewable resources. Furthermore, it promotes the responsible use of water and recycled materials [8].

The background principals for organic management practices are: maintaining the biological fertility and activity of the soil and that the fight against parasites, diseases and weeds should be by biological processes. To maintain biological fertility and activity of the soil, appropriate rotation systems, incorporation of organic materials in soils and crop associations in the same land are used. To fight parasites, diseases and weeds, it is important to choose species and appropriate varieties, promote rotation systems, mechanic methods and biological control (using biologic enemies of the parasites and diseases) [8].

\subsection{Optidose integrated production vineyard}

According to the definition adopted by OILB/SROP Organisation Internationale de Lutte Biologique et Intégrée/Section Régionale Ouest Paléarctique) - in 1992, integrated production is an agricultural system that produces high quality food and others using natural resources and measures. This way, using any agriculture practices that harm the environment are avoid, enabling a long term viability of agriculture [9].

Integrated production is conducted by the following principals [9]:

- Regulation of the ecosystem, importance of animal welfare and preservation of natural resources;

- Understanding the farm as the integrated production implementation unit;

- Regular updating of farmers knowledge about integrated production;

- Maintaining the stability of agrarian ecosystems;

- Balance the nutrient cycle, reducing losses to a minimum;

- Preservation and improvement of soil intrinsic fertility;
- Promotion of biodiversity;

- Understanding the quality of agriculture products based on ecological parameters;

- Protection of plants based on the objectives and guidelines of integrated protection;

- Minimization of some of the side effects of agricultural activities.

However, integrated production and optidose integrated production are not the same. This difference is based on the doses of the products that are used on the fields. In optidose integrated production all the doses of the products added are optimized. The problem is identified and analysed, and the recommended fabricant doses are adjusted to each case according to the environment conditions and vegetative development of the plants. This way if we can use less pesticides or herbicides to fight the problem we only apply the doses that are necessary [9].

\subsection{Conventional vineyard}

The present study considers a conventional vineyard as one with local and regional characteristics. These agricultural practices use chemical herbicides and pesticides inputs (allowed by CVRA) to increase productivity, without caring about the environment and biodiversity.

\section{The group of macroinvertebrates to monitor: Coleoptera, Hymenoptera and Hemiptera}

Coleoptera is the biggest order of the class Insecta, with 400 thousand species. This order includes mostly beetles [10]. It is divided in four different suborders: Archostemata, Myxophaga, Adephaga and Poliphaga $[11,12]$.

Coleoptera insects are easily distinguished by their specialized fore-wings, which are typically modified into hard wing cases (elytra) and are used to protect the hind wing and abdomen. The elytra are also the wigs that they use to fly [10].

These beetles can be found in a diverse amount of habitats where insects live and have a varied diet. However, they are mostly predators [13]. Also, they are widely used as bioindicators of the environmental quality and degradation [14].

Hymenoptera is also one of the most important and abundant orders of insects and they can be found in a wide variety of terrestrial habitats [15]. It represents the Adrenidae, Apidae, Halictidae, Colletidae and Megachilidae families, which includes insects like bees, wasps, ants and mosquitoes. These are mostly parasitoids, predators and mainly pollinators [16].

The Hemiptera order also has a good representation in the class Insecta with 65 thousand species. These are mostly phytophagous insects, feeding from the plant sap. However, they can also be hematophagous. This order includes bedbugs, aphids and leafhoppers, which all have a mouth-sucking mouth peace [17].

Initially, this order was divided into two suborders, the Heteroptera and the Homoptera. However, more recent studies have concluded that some insects of the Homoptera suborder were not as close as they thought and this order was divided in Auchenorrhyncha, Coleorryncha and Sternorryncha [17]. 


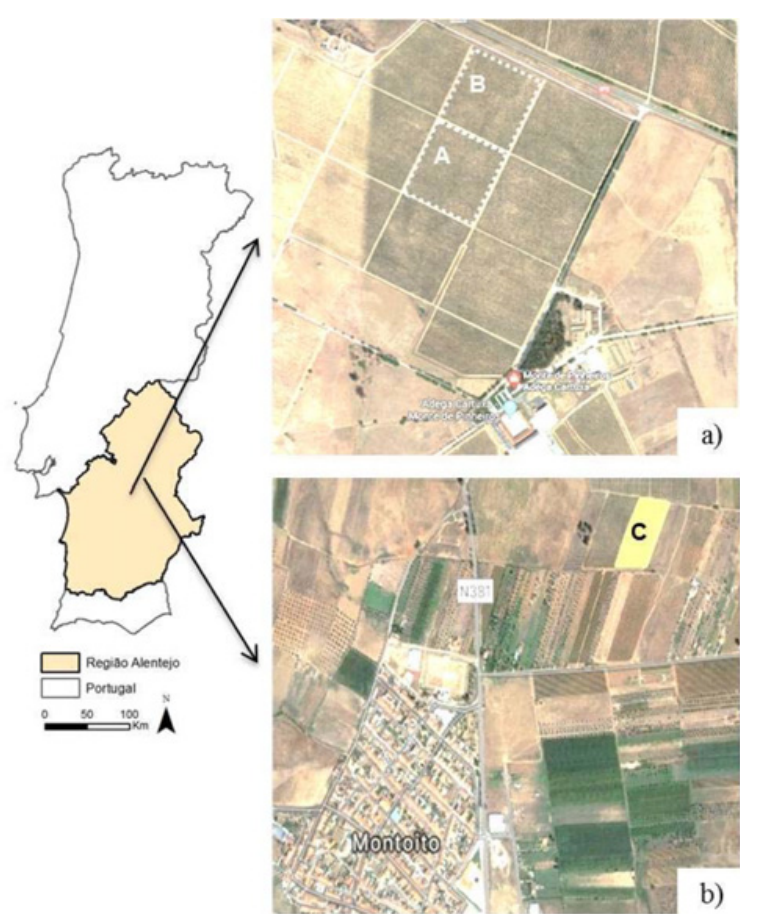

Figure 1. Location of the three vineyards in Portugal. a) Satellite image of the Herdade dos Pinheiros plots (Casito), Évora. A Optidose integrated production. B - Organic; b) Satellite image of the Montoito plot (Gorita), Redondo. C - Conventional.

\section{Methods}

\subsection{Study area}

The study area is Herdade dos Pinheiros da Fundação Eugénio de Almeida, located nearby Évora (Alentejo, south Portugal). The climate of the region is Mediterranean with continental influence (a well-marked wet season during autumn and winter and a very hot and dry season during summer). The continental influence is notorious due to the great amplitudes verified during the day as well as along the year.

In Herdade dos Pinheiros there are both organic and optidose integrated production vineyards. This allowed to have a control on the variable factors such as climate and soil quality, so the only factors influencing the biodiversity and the productivity are the different agricultural practices.

Unfortunately, for our study, in Herdade dos Pinheiros there is no conventional vineyard. So, we chose one vineyard in another location, with the same type of climate and soils, to allow comparisons between the three types of vineyards.

The conventional vineyard studied is located in Montoito, Redondo, also in region Alentejo, south Portugal, $30 \mathrm{~km}$ far from Herdade dos Pinheiros. Figure 1 shows the location of the three vineyards.

In Herdade dos Pinheiros we choose one plot of optidose integrated production vineyard and one plot of an organic vineyard Fig. 1a, in Casito vineyard. In Montoito we choose one plot of a conventional vineyard Fig. 1b, the Gorita vineyard.

\subsection{Characterization of the vineyards}

According to Dellenne (2008) [18], the main aspects for the characterization of a vine are: the area and age, the installation (e.g., distance between plants and distance between lines), orientation, soil type and conditions, irrigation and interlines cover. Accordingly, we tried to select the three vineyards (plots) in a way that these aspects were constant.

On the other hand, all the plots we choose are from the variety Trincadeira, in order to eliminate differences between productivity levels resulting from the variety of the grape. The variety Trincadeira is common in the Alentejo and Douro regions. It normally has high productivity levels, compared to others, and it's a red variety with medium and compact bunches. This particular variety is vulnerable to diseases and rot.

Regarding the plots from Herdade dos Pinheiros, they both have 20 years old, $2.50 \mathrm{~m}$ between each line and $1 \mathrm{~m}$ between each plant. So, the plant density is 4000 plants/ha. Each plot has 83 lines with $200 \mathrm{~m}$ each and a NorthwestSoutheast orientation.

The organic vineyard plot is 4.08 ha and all the treatments allowed are cupper, sulphur or natural products. They control the herbs in the vines lines mechanically with a machine that cuts the herbs $40 \mathrm{~cm}$ far from each side of the line. For fertilization they only use organic matter. Pruning is done in green and they also defoliate and irrigate the vines. Pruning in green means to cut some branches of the plant to promote the growth of the most productive ones. Defoliation is the reduction of the vegetative parts, promoting the circulation of air and being a strategy for the control of diseases that affect leaves.

The optidose integrated production vineyard plot is 4.14 ha. The treatments include chemical pesticides and herbicide, but the doses are regulated according to the size of the herbs or the risk of disease. In Portugal, the allowed products are all the ones indicated by the Direção Geral de Alimentação e Veterinária (DGAV). They control the weeds in the vines lines with herbicides and the fertilization is archived with ternary fertilizers. They also irrigate these vines.

Weed management and soil cover influence vineyards and its levels of biodiversity. It is important to control erosion and limit the action of plagues, promoting refugee for auxiliary insects. In long term, these practices may promote accumulation of organic matter and enhance the biological control and soil drainage [19]. In Herdade dos Pinheiros, both of the study plots have under-sowing. However, in the organic plot they have direct sowing of legume plants (like vetch and trefoil) and grasses (like oats and rye). On the other hand, the optidose integrated production plot has natural under-sowing.

Regarding the conventional vineyard in Montoito, (Redondo), the Gorita plot, we look for similar characteristics of those in Herdade dos Pinheiros vineyards. We manage to have a Trincadeira plot, but with only 16 years old (4 years younger). Distance between lines is $2.80 \mathrm{~m}$ and between plants is $1.20 \mathrm{~m}$, that makes plant density lower, 3000 plants/ha. Orientation of the line is also different, Northeast-Southwest. This vineyard has 27 lines with $256 \mathrm{~m}$ and the total area of the plot is $1.25 \mathrm{ha}$.

The treatments allowed by DGAV are pesticides, herbicides, growth biostimulators, but there is no caution in the dose control. Weed management is done with herbicides and fertilization with ternary fertilizers. The interlines are plowed three times a year (winter, spring and 


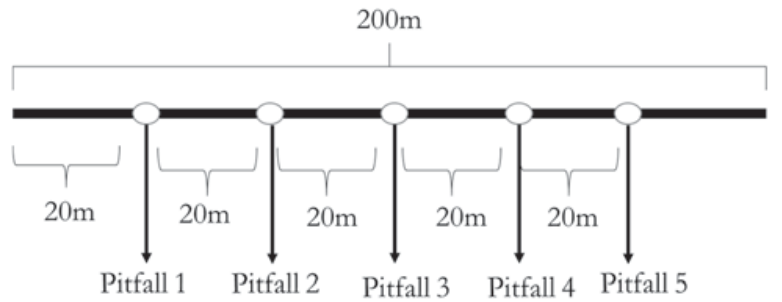

Figure 2. Installation of the pitfall traps in each line.

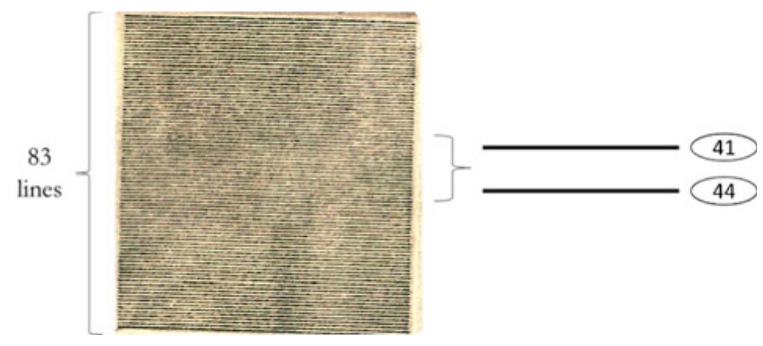

Figure 3. Organic plot of the Herdade dos Pinheiros vineyard showing the lines that were sampled.

summer) which disables the growth of interline soil cover. This vineyard is also irrigated.

\subsection{Monitoring macroinvertebrates and biodiversity data}

We are studying Coleoptera, Hymenoptera and Hemiptera. Monitoring of these insects group was accomplished by pitfalls and coloured plates.

Regarding the pitfall method, we did 4 samplings for each plot (organic, optidose integrated production and conventional) with 10 sampling points each (total 40 samples for each vineyard) and 15 days between the samplings.

In each plot we installed 10 pitfalls in two of the central lines ( 5 in each) to avoid edge effects. Pitfall traps were $20 \mathrm{~m}$ apart from each other and from the beginning of the line Fig. 2. For the Herdade dos Pinheiros vineyards we studied lines 41 and 44, as shown in Fig. 3. For the Gorita vineyard we studied lines 13 and 16 .

For the coloured plates we did 2 samplings for each plot with 5 sampling points each (total 10 samples for each vineyard). We placed 5 plates in each vineyard $20 \mathrm{~m}$ apart from each other and from the beginning of the line. The plates stayed on the field for four hours and the sampling happened in the same day as they were installed.

For the Herdade dos Pinheiros optidose integrated production vineyard, we studied line 44 , and for the organic vineyard line 41. In Gorita vineyard we placed the plates in line 13 .

The sampling was made from June to August 2018. Identification of macroinvertebrates is ongoing (September 2018).

Screening and identification will give all the data we need to evaluate the biodiversity in the three different vineyards. Values of abundance and diversity of species are going to be calculated to fulfil the final goal of the study, comparing the biodiversity of the different vineyards.

\subsection{Productivity data}

Productivity data will be calculated with information provided by the owners of Herdade dos Pinheiros and Gorita vineyard. Comparing the mean values of productivity of the last 5 years will allow to evaluate the differences between the three vineyards.

\subsection{Statistical analysis}

Biodiversity data will be abundance and diversity of Coleoptera, Hymenoptera e Hemiptera macroinvertebrates.

Statistical analysis will be accomplished by means of Multivariate Principal Components Analysis. This will give us information about the significance of the differences between the three vineyard plots (organic, optidose integrated production and conventional).

Productivity date will also be analysed by means of Multivariate Principal Components Analysis to explain the significant differences between the average levels of productivity of the different plots.

For the statistical analysis we will use R 3.4.3.

\subsection{Conservation actions}

Biodiversity data and productivity will be compared to identify the most sustainable agriculture practices in vineyards. This way, we will be able to suggest measures to enhance biodiversity of vineyards and surrounding areas and keep high levels of productivity for famers benefit.

\section{Expected results}

The study is still in course, so the results presented are what we are expecting to find.

We predict that different agriculture practices will affect the insects biodiversity, meaning these values will be different in the three vineyards studied. Furthermore, levels of productivity should as well be different for the three vineyards. This way, we will explore the effects of each agriculture practices in the levels of biodiversity and productivity.

Higher disturbance means that the levels of biodiversity will be lower [7]. We are expecting to find higher levels of biodiversity and lower levels of productivity in an organic vineyard compared to a conventional vineyard. However, the optidose integrated production may present intermediate levels with high levels of biodiversity and rentable productivity.

We also expect to find lower abundance and diversity of Hemiptera when levels of abundance and diversity of Coleoptera and Hymenoptera is higher. This means that a vineyard with high levels of abundance and diversity of predator macroinvertebrates, as Coleoptera and some Hemiptera, has a better biological control for plagues and diseases. This way, lower disturbance will determine higher biodiversity levels and a better biological control. For this, the presence or absence of soil cover in the interlines will be important. We hope to find higher diversity and abundance of macroinvertebrates in vineyards with higher diversity of soil cover plants [7]. 


\section{Final remarks}

Agriculture is the dominant land use activity in Europe and, due to its intensification, it has a great impact in biodiversity loss nowadays. As viticulture is one of the most important agriculture activities it can be used as an entrance point of sustainable practices in agriculture. This way, we will determinate the most sustainable agriculture practices in vineyards to enhance biodiversity levels and keep high productivity levels using insects monitoring. From the results, we will suggest measures for conservation biodiversity in vineyards to enhance sustainability in viticulture and, in long term, agriculture and surrounding areas.

\section{References}

[1] R.A. Robinson, W.J. Sutherland, J. Appl. Ecol. 39, 157 (2002)

[2] T.G. Benton, J.A. Vickery, J.D. Wilson, Trends Ecol. Evol. 18, 182 (2003)

[3] T. Tscharntke, A.M. Klein, A. Kruess, I. SteffanDewenter, C. Thies, Ecol. Lett. 8, 857 (2005)

[4] K. Belfrage, J. Björklund, L. Salomonsson, Agroecol. Sustain. Food Syst. 39, 170 (2015)

[5] S.J. Scherr, J.A. McNeely, Philos. Trans. R. Soc. B Biol. Sci. 363, 477 (2008)

[6] J. Viers, J. Williams, K. Nicholas, O. Barbosa, I. Kotzé, L. Spence, L. Webb, A. Merenlender, M. Reynolds, Conservation lett. 6, 287 (2013)

[7] L.J. Thomson, D.J. Sharley, A.A. Hoffmann, Aust. J. Exp. Agric. 47, 404 (2007)

[8] I. Barrote, Manual de Conversão ao modo Biológico, Divisão de Produção Agrícola. Direção Regional de Agricultura e Pescas do Norte. Available in: http://www.drapn.min-agricultura.pt/ drapn/prod_agric/fil_bio/manual_convers\% C3\%A3o.pdf, consulted in 10-03-2018

[9] Direção Geral de Agricultura e Desenvolvimento Sustentável. Modos de produção Sustentável e valorização da qualidade. Produção integrada. Available in: http://www.dgadr.gov.pt/susten tavel/producao-integrada, consulted in 10-032018

[10] D.J. Borror, D.M. Delong, In Introdução ao Estudo dos Insetos, edited by B. São Paulo (Brasil, 1969)

[11] F. Martín-Piera, J.J. Morrone, A. Melic, Hacia un proyecto CYTED para el inventario y estimación de la diversidad entomológica en Iberoamérica (Zaragoza: Sociedad Entomológica Aragonesa, 2000), p. 99

[12] J.F. Lawrence, A.M. Hastings, M.J. Dallwitz, T.A. Paine, E.J. Zurcher, Beetles of the World: A Key and Information System for Families and Subfamilies. (Melbourne, CSIRO, CD-Rom, 1999)

[13] R.C. Marinoni, N.G. Ganho, M.L. Monné, J.R.M. Mermudes, Hábitos Alimentares em Coleoptera (Insecta) (Ribeirão Preto, Holos, 2001), p. 63

[14] P.G. Silva, F.C.G. Silva, Besouros (Insecta: Coleoptera) utilizados como bioindicadores. Revista Congrega URCAMP 5, 1 (2011)

[15] P.E. Handson, I.D. Gauld, Memoirs of the Am. Entomological Inst. 77, 1 (2006)

[16] M.J. Sharkey, F. Fernández, Introducción a los Hymenoptera de la Región Neotropical (Sociedad Colombiana de Entomología y Universidad Nacional de Colombia, 2006), p. 93

[17] T.R.E. Southwood, D. Leston, In Land and Water Bugs of the British Isles, edited by F. Warne (Londres, Inglaterra, 1959)

[18] C. Delenne, S. Durrieu, G. Rabatel, M. Deshayes, J.S. Bailly, C. Lelong, P. Couteron, Int. J. Remote Sensing. 29, 1153 (2008)

[19] Plano de conservação do solo. Boletim informativo (2014) Associação para o Desenvolvimento da Viticultura Duriense. Available in: http://www. advid.pt/imagens/boletins/14162368662496. pdf, consulted in 23-05-2018 